\title{
The Use of Venom and Venom-Derived Products in Medicine and Cosmetics: the Ethical Issues From Islamic Perspective
}

\author{
Muhamad Rusdi Ahmad Rusmil ${ }^{1}$, lekhsan Othman ${ }^{2}$, Che Anuar Che Mohamad ${ }^{1}$ \\ ${ }^{1}$ Kulliyyah of Pharmacy, International Islamic University Malaysia , ${ }^{2}$ Jeffrey Cheah School of Medicine and \\ Health Sciences, Monash University Malaysia.
}

\begin{abstract}
Venom is a mixture of biologically active toxins that affect normal physiological functions. With the advance in technology, the complexity and functions of venom and its toxins are slowly being revealed. It has become important source for therapeutic, diagnostic and cosmetic agents. However, there is concern among the Muslim community pertaining to halal and safety issues on the venom and venom-derived product usage. There are few studies that discuss the Islamic views in the usage of venom and venom-based product in medicine and cosmetic applications. There is a need for Muslim scientists and scholars to seriously identify the potential ethical and safety issues in the usage of venom and venom-derived products in view of the widespread application in medicine and cosmetic, which subsequently forming the basis for relevant and reliable shariah ruling. This is an attempt to review the relevant articles based on the following keywords: venom and Islamic ruling, venom-based product, venom and medicine, venom and cosmetic, antivenom, venom toxin, snake poison and venom diagnostics. It will also attempt to clarify and elaborate the implication of the "halal" status for venom-based product. Finaly the current available shariah rulings on the usage of venom and venom-based product both in medical and cosmetic area and the related principle of figh involved will be analyzed. The findings from this review, particularly the current available ruling will allow various parties to be well informed on the current ruling and related issues on the usage of this products.
\end{abstract}

KEYWORDS: Venom, Venom-derived, Medicine, Cosmetic and Halal

\section{VENOMOUS ANIMALS, VENOMS AND TOXINS}

Venomous animals have specialized organs called venom apparatus to produce and deliver a cocktail of bioactive molecules called venom to the intended prey or predator ${ }^{1}$. Venomous species can be found in nearly all classes of animals, except in birds. Venomous animals use venom as a tool for immobilizing their prey, digesting their prey and as deterrence from their predator. The venom apparatus consists of venom glands and a venom delivery organ which may be a fang, spur, stinger, bristle, nematocysts, barb or spine. ${ }^{1}$ The venom apparatus is unique to the particular genus of venomous animals as it produces and delivers, as each genus has its own distinctive biomolecule composition in the venom and delivery organ.

The bioactive molecules in the venom are considered as toxins because of their capability to alter the normal physiological functions in their prey or predator, e.g. cardiovascular system, coagulation system and nervous system. These toxins selectively bind and cause changes at the specific receptors at the target body systems. ${ }^{2}$ The composition of the venom varies from species to

Muhamad Rusdi Ahmad Rusmili Department of Basic Medical Sciences, Kulliyyah of Pharmacy, International Islamic Üniversity Malaysia, Kuantan Campus.

Email: rusdirusmili@iium.edu.my species, for example, the composition of snake venom will not be the same as the composition of venom in the scorpion. A venom could contain proteins, peptides, small molecules and inorganic salts, depending on the species. In snake venom for example, the major component in the venom is protein whereas, there are more peptides in scorpion venom. Variation of the composition of the venom in venomous animals have been reported in various animals. The composition could vary depending the geographical locality, diet, sex, and season when the venomous animals were milked. ${ }^{3}$ The venom variation has a significant impact in the treatment of the snake envenoming and may have significant impact in the discovery of drugs as it may affect the abundance of starting material for study.

\section{EXAMPLES OF VENOM AND VENOM-DERIVED PRODUCTS IN MEDICINE AND COSMETICS}

Translation of the knowledge on the bioactivity of venom into medicine is not something new. Venoms have been documented to be used in ancient and traditional medicine in various cultures and civilizations. In ancient Greek, Agari doctors were reported have saved King Mithradates of Pontus from bleeding to death from his battle wound using venom from steppe viper. In Indian Ayurvedic medicine, Indian cobra venom is used as one of the component in the Ayurvedic tonic called "Suchikabharana". ${ }^{4}$ Scorpion venom is used widely in traditional Chinese medicine to treat diseases such as cardiovascular disease, chronic pain and convulsion. ${ }^{5}$ 
Venom-derived products can be defined as the products of isolation, modification, or synthesis of the bioactive molecules of interest from the molecules in the venom or based on the molecules in the venom. These products mimic the activity of the specific toxin in the venom. In modern times the development of an anti-hypertensive drug from venom, angiotensin converting enzyme inhibitor (ACE inhibitor) is one of the success in venom knowledge translated to medicine.The ACE inhibitor was developed based on the bradykinin-potentiating peptide which was isolated and discovered in from Bothrop jararaca, a pit viper species found in South America. ${ }^{6}$

Below are other examples of the use of venom and venom-derived products in medicine and cosmetics:

\section{Antivenom}

Antivenom is the only clinically proven biopharmaceutical products used to treat envenoming and classified as one of the essential biopharmaceutical by World Health Organization. ${ }^{7,8}$ It is produced by injecting a sub-lethal dose of venom to a host animal e.g. horse, sheep, goat or camel, to allow the host immune system to generate antibodies against the venom which later, can be collected, purified and modified to make it functional and less immunogenic. ${ }^{7}$ The monovalent antivenom is a type of antivenom that can only neutralize toxicity effects caused by a single species or species with cross-neutralization activity, whereas the polyvalent antivenom is a type of antivenom that can neutralize toxicity caused by several species. ${ }^{7,8} \& 9$

The immunoglobulins in the antivenom bind to the free circulating venom toxins in the circulation of the victim and prevent them from binding to the receptors on the cells to cause their toxic effects. Early administration of antivenom is crucial in the management of envenoming in emergency department, as delaying antivenom will cause further damage to the cell, tissue and organ of the victim. This will dramatically increase the risk of morbidity and mortality from the toxic effects of the venom. ${ }^{7 \& 10}$ Eventually, this will reduce the economic burden to the health of the victim.

\section{Bee venom therapy}

Apitherapy is a complementary treatment that use products from bees for health improvement. Bee venom contains various protein,s peptides and small molecules that have enzymatic and inflammatory mediation effects. The venom and its constituents have been found to have anti-arthritic, antinociceptive and anti-cancer effects. ${ }^{11,12,13 \& 14}$ In this therapy, live bees will be harvested from bee hive box and the patient will be deliberately envenomed at certain locations in the body, ideally at the parts where there is illness. ${ }^{15}$ \& 16 This therapy has been used to treat inflammatory diseases, managing pain and claimed to have anticancer activity. Some practitioners combine the meridian and acupuncture knowledge in traditional Chinese medicine to have combination effects. The application of bee venom at the acupoints was found to exert longer therapeutic effects than application at the nonacupoints. ${ }^{15,16,17 \& 18}$ Crude bee venom is also being used as the active ingredient in topical anti-wrinkle cosmetic preparations. The venom has been shown to have anti-wrinkling effects in animals. ${ }^{19}$

\section{Cobratoxin}

Cobratoxin is one of the toxins found in the cobra venom that inhibits nicotinic acetylcholine receptors and it is classified as a neurotoxin as it is capable of altering neurotransmission in cholinergic system. ${ }^{20}$ It binds, blocks and modulates both nicotinic and muscarinic acetylcholine receptor systems to potent pain relieve. ${ }^{5,21,232 \& 23}$ There are topical products that claimed to contain cobratoxin for human use but the effectiveness in human is doubtful. Cobratoxin is also considered as one of the illegal drugs used in horse racing as it blocks pain sensation in the race horses. ${ }^{24}$

\section{Mimetics of Temple's viper venom}

Waglerins are unique neurotoxins that were isolated from Temple's pit viper. They bind and block to nicotinic acetylcholine receptors, causing paralysis in isolated mouse tissue preparation. A mimetic of waglerin-1, dipeptide diaminobutyroyl benzylamide diacetate, has been commercialized as an active ingredient in anti-aging cream. The peptide works nearly similar to Botox, paralysing the facial muscles which temporarily reduces the wrinkle. The effectiveness of the mimetics as anti-aging preparation is not fully known but it has been shown to able to reduce wrinkle when combined with conventional anti-aging treatment. ${ }^{25}$

\section{THE DANGERS OF USING VENOM AND VENOM- DERIVED PRODUCTS IN MEDICINAL AND COSMETIC PREPARATION}

There is always a risk for the venom-based or venom-derived products as it may cause serious side-effects. These products contain highly potent toxins or modified molecules based in the toxin found in the venom that can alter normal physiological function. Toxicology study and sideeffects profiling are relatively less complicated for the isolated toxins or modified toxins compared to crude venom. In the case of venom-derived products, the complexity nature of the crude venom makes it harder to be utilized in controlled manner as the bioactive molecules in the venom simultaneously bind and exerting effects on various body systems. The bioactive molecules in the venom and venom-derived products have a tendency to induce hypersensitivity reaction to the user, similar to the risk in the use of the other pharmaceutical agents, even at claimed therapeutic dose. The composition of the venom could vary from species to species, sex, diet, geographical locality and seasons. ${ }^{3 \& 26}$ These factors will affect the 
composition of the toxins in the venom, the potency and side effects. A system of controlled environment and sampling is necessary to control venom quality in order to use the crude venom as an active ingredient. Similarly, tvenom-derived product requires a system that allows the venom derivatives to be isolated or synthetized as pure bioactive molecules. The potency of isolated/ synthetized biomolecules will be higher than the venom as no other contaminants or non-active compounds are present. This will enhance the potential of sideeffects dramatically.

\section{THE PERMISSIBILITY AND ETHICAL ISSUES RELATED TO THE USE OF VENOM AND VENOM-DERIVED PRODUCTS}

There are several factors that need to be considered in this issue by Muslim clerics and scientific/medical personnel, such as:

\section{The source of the venom from venomous/ poisonous animals, \\ 2.The complex nature of the crude venom, 3. The indication of usage \\ 4.the documented and potential risk of its application in human}

Further to the textual religious knowledge and legal maxim, these 4 issues are thus far the known fundamental issues that need to be discussed and carefully scrutinized in order to determine the halal status of the venom-derived products, and its permissibility to be used in medicine and/or cosmetics. Previous Muslim scholars and medical practitioners have expressed mixed response to the use of forbidden and impure materials in medication. The original ruling is obviously unlawful (haram) for Muslim to consume any impure foods/materials which is derived from the certain animals such as swine and by-products, animals with fangs such as tigers and snake and animals having toxins/poisons or producing ill effects if ingested such as snake and certain type of fish. The prohibition is understood from the textual analysis of the Quranic verses and Hadith such as the following:

"He has forbidden you only the dead animals, and blood, and the flesh of swine..." (2: 173).

"...for he (the Prophet) commands them what is just and forbids them what is evil; he allows them as lawful what is good (and pure) and prohibits them from what is al-khabaa'ith bad (and impure)..." (Surah al-A'raf, : 157.)

From this verse, the scholars including al Shafie interpret that the word khabaaith as the vermin of the earth such as snakes, scorpions, dung beetles, cockroaches, rats etc. and these animals are haram for Muslims to consume.

However, in the state of extreme necessities (dharurah), it is permissible to use medicine form non-halal materials as long as the halal alternatives is not available according to majority of the scholars. This permissibility is based on one of legal maxim "necessities will legitimize the prohibition". This exceptional rule is applicable in the case of dire necessity for medical reason including the use of the venom and venom-derived products to save life. This position is also supported through the permissibility of using silk for skin treatment from the Hadith which showed that the Prophet (PBUH) allowed some of his companions to wear silk which was originally ruled as haram for men (Narrated by al-Bukhari and Muslim). This hadith is taken as a basis by some jurist of the Shafi'ites to allow the use of other forbidden materials for medicine. Another evidence which indicate the permissibility of the use of forbidden and impure substance for therapeutic reason is the Hadith narrated by alBukhari and Muslim where the Prophet (PBUH) allows the use of camel urine as a cure for the stomachache. ${ }^{27}$ According to the majority of the jurists including al-Shafie and Abu Hanifi, camel urine is considered impure and unclean, thus its permissibility from the Prophet $(\mathrm{PBUH})$ reflecting the validity of the opinion to allow its use for the sake of treatment and not because it is pure in principle.

There is different view from other jurists who regard the urine of the animals that are fit for consumption is clean, thus it is permitted to be consumed. ${ }^{28}$ The lengthy discussion on the purity of the animal urine could be further referred in the book of fiqh like Bidayatul Mujtahid etc. Based on the Hadith that relate the permissibility of camel urine for medicine, some Muslim jurists from the school of the Hanafi and al-Qadi al-Tabari from the Shafi, have agreed on the permissibility in using intoxicants for medication if fulfilled with certain requisites which are : (i) It is the only possible cure and no other alternatives could be found in that particular situation, (ii) The prescription must be in a small amounts and should not intoxicate the mind and (iii) A Muslim doctor must prescribe it as his commendation in this matter is considered as a responsibility and a kind of legal testimony. ${ }^{29}$

The above evidences and discussions indicate that in Islam, the use of venom is generally prohibited as this substance is considered impure. The same ruling would also have applied to any venom-derived products in the market. The impurity is due to its derivation from unlawful animals of poisonous nature such as snake and scorpion. These poisonous animals like snake could also fall under the category of animal with fangs, a character of animals which are considered as haram. Nevertheless, the usage of this substance is permissible for medical purposes under the principle of necessity (dharurah) if there is no other available halal alternative and the patient's life is at stake. This is the opinion of traditional Hanafi jurist and preferred by many contemporary scholars. ${ }^{30}$ A more specific ruling to the use of antivenom could be found from Al-Khatib Ash-Shirbini who wrote in Mughni Al-Muhatj (4/234):

"It is permissible to take anti venom and the like 
mixed with alcohol which has become completely indistinguishable (such that no color, taste, or odor remains) if a cure made from pure substances is unavailable. Examples include medication with ritually impure substances such as snake meat and urine which are permissible even if for the purpose of hastening recovery. This permissibility rests upon the prescription of an upright Muslim physician or the patient's own knowledge of the [healing properties] of the impure substance."

The concept of darurah is generally agreed upon by the jurists from different schools of jurisprudence but they do differ in determining the different type of prohibited substances which can be used as medicine.

We may apply the permissibility of using the venom or venom-derived product for valid medical reason under following conditions:

1.The patient's life is endangered without the treatment

2.No alternative from entirely halal (lawful) sources 3.The medication is prescribed by a Muslim physician who is knowledgeable and righteous (subject to more discussions)

Among the examples of the permissible venomderived product is the use of antivenom to treat systemic envenoming cases e.g. snake envenoming, in medical emergencies. The permissibility is due to the life-threatening nature of the venom and the antivenom has been showed to be effective and only reliable option from clinical data. In fact, prior to it usage, the effectiveness and the safety have been established from the randomized controlled clinical trials. Otherwise the exemption for the usage of venom and venom-derived product is tolerated in the extreme necessity where the circumstances of extreme necessity have to be proven and justified (like the envenoming effect as a result of snake bites). Additionally, to the authors knowledge, the available evidence do not seem to exempt the use of venom for cosmetic reason and beauty product application, such as the usage as anti-aging cream. Therefore, from Islamic and ethical point of views, the authors are inclined to discourage the use of venom and venom-derived product in cosmetic and beauty products as the desire for external beauty is not considered a necessity. In such cases it would be forbidden to consume or apply venom which impure and potentially cause dangerous and lifethreatening side-effects to the user. The prohibition is not merely due to impurity of the substances but also because of the risks of dangerous side effects such as hypersensitivity, blood coagulation disorder and skeletal muscle paralysis.

\section{CURRENT ISLAMIC RULINGS FOR THE USE OF THE VENOM AND VENOM-DERIVED PRODUCTS}

To date, there are no specific and official verdict on the usage of venom and venom-derived products from Muslim authorities or regulatory bodies, including the fatwa Committee of National Religious Council. The Fatwa Committee of the National Council of Islamic Religious Affairs has consistently discussed the religious rulings on various issues in medicine including the cases involving the utilization of forbidden materials. The closest to is probably the case involving the usage of Botulinum Toxin Type A or botox injection. According to the committee, such injections for cosmetic purposes is not permitted but is allowed if prescribed due to medical reason and necessity based on the maxim of darurah. From the ruling on botox injection, the use of venom and venom-derived product may not be permitted except for valid medical reason as briefly discussed above. While we are not in the position to issue a specific ruling on the use of venom and venom-derived products in cosmetic, we may at least suggest that their use for cosmetic purposes should be regarded as forbidden until further discussion is held by both academic and religious authority, involving both the religious scholars and scientists.

\section{CONCLUSION}

While the medical advancement has further expanded the potential use of the venom, the review of the available references show that venom is generally considered impure based on the Islamic textual analysis. Therefore, the use of venom and venom derived product are generally prohibited except in the case of necessity (dharurah) e.g. for valid medical reasons. The limitation and scarcity of the contemporary literatures and guidelines concerning the ethical issues on the use of venom and venom-derived product necessitate more effort from both scientific communities and religious scholars. This is toward meaningful collaboration and production of academic publications. In addition, it is also important to come out with a specific guideline from the relevant Islamic regulatory bodies on the ethical use of venom and venom-derived product in grappling with the advancement of the contemporary medicine and cosmetics. Finally, it is our hope that this brief discussion on ethic and figh on venom and venom derived products would spearhead further discussions on the topic for the benefit of the society at large.

\section{REFERENCES}

1. Mackessy, S. P. Handbook of venoms and toxins of reptiles 2006. CRC Press.

2. Harvey, A. Snake venom peptides. In A. J. Kastin (Ed.), Handbook of biologically active peptides 2006 (pp. 355-362). London: Academic Press.

3. Fry, B. G., Winkel, K. D., Wickramaratna, J. C., Hodgson, W. C., \& Wüster, W. Effectiveness of snake antivenom: species and regional venom variation and its clinical impact. Toxin Reviews, 2003; 22:23-34.

4. Roy, P. K., Ray, G. K., Dutta, A. T., \& Mukerji, B. Studies on Suchikabharana an 
Ayurvedic tonic preparation of cobra venom. Indian J Med Res, 1952; 40:101-107.

5. Zhang, L., Zhang, Y., Jiang, D., Reid, P. F., Jiang, X., Qin, Z., \& Tao, J. Alpha-cobratoxin inhibits T-type calcium currents through muscarinic M4 receptor and Gomicron-protein betagamma subunits-dependent protein kinase A pathway in dorsal root ganglion neurons. Neuropharmacology, 2012;62: 10621072.

6. King, G. Venoms to drugs: translating venom peptides into therapeutics. Australian Biochemist, 2013; 44.

7. Ratanabanangkoon, K., Tan, KY., Eursakun, S., Tan, CH., Simsiriwong, P., et al. A simple and novel strategy for the production of a pan -specific antiserum against elapid snakes of Asia. PLOS neglected tropical diseases, 2016; 10.

8. Warrell, DA. Snake Bite. The Lancet. 2010; 375: 77-88.

9. Warrell, DA. The clinical management of snake bites in the Southeast Asian region. Southeast Asian J Trop Med Public Health, 1999; 30 (Suppl 1):1-67.

10. Rusmili MR, Tee TY, Mustafa MR, Othman I, Hodgson WC. Isolation and characterization of a-elapitoxin-Bf1b, a postsynaptic neurotoxin from Malaysian Bungarus fasciatus venom. Biochemical pharmacology. $2014 \mathrm{Mar}$ 15;88:229-36

11. Billingham ME, Morley J, Hanson JM, Shipolini RA, Vernon CA. An anti-inflammatory peptide from bee venom. Nature. 1973 Sep;245 (5421):163.

12. Chen, J., \& Lariviere, W. R. The nocicep tive and anti-nociceptive effects of bee venom injection and therapy: a double-edged sword. Progress in neurobiology, 2010;92:151-183.

13. Son, D. J., Lee, J. W., Lee, Y. H., Song, H. S., Lee, C. K., \& Hong, J. T. Therapeutic application of anti-arthritis, pain-releasing, and anti-cancer effects of bee venom and its constituent compounds. Pharmacology \& therapeutics, 2007;115:246-270.

14. Zurier, R., Mitnick, H., Bloomgarden, D., \& Weissmann, G. Effect of bee venom on experimental arthritis. Annals of the rheumatic diseases 1973; 32:466.

15. Kim, W., Kim, M. J., Go, D., Min, B.-I., Na, H. S., \& Kim, S. K. Combined effects of bee venom acupuncture and morphine on oxaliplatin-induced neuropathic pain in mice. Toxins 2016; 8:33.

16. Kwon, Y.-b., Lee, J.-d., Lee, H.-j., Han, H.j., Mar, W.-C., Kang, S.-k., Lee, J.-h. Bee venom injection into an acupuncture point reduces arthritis associated edema and nociceptive responses. Pain 2001 90: 271-280.

17. Lee, J.-D., Park, H.-J., Chae, Y., \& Lim, S. An overview of bee venom acupuncture in the treatment of arthritis. Evidence-based complementary and alternative medicine, 2005; 2:79-84.
18. Lee, M. S., Pittler, M. H., Shin, B.-C., Kong, J. C., \& Ernst, E. Bee venom acupuncture for musculoskeletal pain: a review. The Journal of Pain, 2008; 9:289-297.

19. Kim, J.-M., \& Kim, Y.-B. The Effect of Bee Venom Therapy on Skin Aging. The Journal of Korean Medicine Ophthalmology and Otolaryngology and Dermatology, 2010; 23:2740.

20. Chen, Z. X., Zhang, H. L., Gu, Z. L., Chen, B. W., Han, R., Reid, P. F., Qin, Z. H. A longform alpha-neurotoxin from cobra venom produces potent opioid-independent analgesia. Acta Pharmacol Sin, 2006; 27:402408.

21. Gong, S., Liang, Q., Zhu, Q., Ding, D., Yin, Q., Tao, J., \& Jiang, X. Nicotinic acetylcholine receptor alpha7 subunit is involved in the cobratoxin-induced antinociception in an animal model of neuropathic pain. Toxicon 2015; 93:31-36.

22. Liu, Y. L., Lin, H. M., Zou, R., Wu, J. C., Han, R., Raymond, L. N., Qin, Z. H. Suppression of complete Freund's adjuvant-induced adjuvant arthritis by cobratoxin. Acta Pharmacol Sin, 2009; 30:219-227.

23. Shi, G. N., Liu, Y. L., Lin, H. M., Yang, S. L., Feng, Y. L., Reid, P. F., \& Qin, Z. H. Involvement of cholinergic system in suppression of formalin-induced inflammatory pain by cobratoxin. Acta Pharmacol Sin, 2011; 32:1233-1238.

24. Bailly-Chouriberry, L., Cormant, F., Garcia, P., Kind, A., Popot, M.-A. S., \& Bonnaire, Y. Identification of a-cobratoxin in equine plasma by LC-MS/MS for doping control. Analytical chemistry, 2013; 85:5219-5225.

25. Heidl, M. Peptides for prolonging youth In: Peptides for Youth 2009(pp. 263-264):

Springer, New York, NY.

26. Chang, H. C., Tsai, T. S., \& Tsai, I. H. Functional proteomic approach to discover geographic variations of king cobra venoms from Southeast Asia and China. J Proteomics, 2013; 89:141-153.

27. Mohd Zharif, M. M., Abdul Murad, A. H., \& Md Yusof, A. F. The use of forbidden materials in medicinal products: an Islamic perspective. Middle-East Journal of Scientific Research, 2013; 13:5-10.

28. Rushd I. The Distinguished Jurist's Primer: A Translation of Bidayat al-Mujtahid, 2 vols., trans. Imran Ahsan Khan Nyazee, Reading, UK: Centre for Muslim Contribution to Civilization. Reading: Garnet Publishing. 2010.

29. Azzam, A.A.Z.,. al-Maqasid al-Shar'iyyah fi alQawa'id al-Fiqhiyyah. Cairo: Dar alBayan,2001.

30. Safian M, Hanani Y. Necessity (darura) in Islamic law: A study with special reference to the harm reduction programme in Malaysia.2010.

31. Al Munajjid, M. S. Ruling on eating insects, vermin and rodents In: islamqa.info. 
Retrieved October 01, 2016, from https:// islamqa.info/en/21901

32. Adam, M. Is It Permissible to Get Botox Injections? Retrieved October 02, 2016, from http://www.daruliftaa.com/node/6688

33. Liu, Z.-R., \& Ji, Y.-H. Scorpion Venom Research Around the World: Chinese Scorpion Mesobuthus martensii Karsch Scorpion Venoms 2015(pp. 383-410): Springer. 